\title{
The Ribosomal Protein RplY Is Required for Pectobacterium carotovorum Virulence and Is Induced by Zantedeschia elliotiana Extract
}

\author{
Huan Jiang, Mengyi Jiang, Liuke Yang, Peiyan Yao, Lin Ma, Chunting Wang, Huan Wang, Gouliang Qian, \\ Baishi $\mathrm{Hu}$, and Jiaqin Fan ${ }^{\dagger}$
}

Department of Plant Pathology, College of Plant Protection, Nanjing Agricultural University, Nanjing, 210095, China.

Accepted for publication 28 June 2017.

\begin{abstract}
Pectobacterium carotovorum subsp. carotovorum strain PccS1, a bacterial pathogen causing soft rot disease of Zantedeschia elliotiana (colored calla), was investigated for virulence genes induced by the host plant. Using a promoter-trap transposon (mariner), we obtained 500 transposon mutants showing kanamycin resistance dependent on extract of Z. elliotiana. One of these mutants, PM86, exhibited attenuated virulence on both $Z$. elliotiana and Brassica rapa subsp. pekinensis. The growth of PM86 was also reduced in minimal medium (MM), and the

reduction was restored by adding plant extract to the MM. The gene containing the insertion site was identified as $r p l Y$. The deletion mutant $\Delta r p l Y$, exhibited reduced virulence, motility and plant cell wall-degrading enzyme production but not biofilm formation. Analysis of gene expression and reporter fusions revealed that the $r p l Y$ gene in PccS1 is up-regulated at both the transcriptional and the translational levels in the presence of plant extract. Our results suggest that $r p l Y$ is induced by Z. elliotiana extract and is crucial for virulence in $P$. carotovorum subsp. carotovorum.
\end{abstract}

Pectobacterium carotovorum subsp. carotovorum is a soilborne facultative anaerobic phytopathogenic bacterium. It has a global distribution and causes soft rot in a wide range of crops and ornamental plants during cultivation, transportation, and storage (Fan et al. 2011b; Joshi et al. 2016a; Kubheka et al. 2013; Ma et al. 2007; Mansfield et al. 2012; Potrykus et al. 2014; Tian et al. 2015; Toth et al. 2003). Like other soft-rot Enterobacteriaceae (SREs), including P. atrosepticum and Dickeya dadantii, $P$. carotovorum subsp. carotovorum is a wellstudied producer of plant cell wall-degrading enzymes (PCWDEs) (Toth and Birch 2005). PCWDEs are secreted mainly by the type II secretion system (T2SS), and several related T2SS regulators have been identified (Charkowski et al. 2012; Hassan et al. 2013; KazemiPour et al. 2004; Li et al. 2010; Lu et al. 2011; Rodionov et al. 2004; Williamson et al. 2010; Yamazaki et al. 2011). SREs have also been shown to possess the effector protein DspE, which is secreted through the type III secretion system (T3SS) to manipulate the host plant defense response and aid infection (Hogan et al. 2013; Jin et al. 2016).

Previous studies revealed that SREs also respond to plant components and small molecules (Babujee et al. 2007; Charkowski et al. 2012; Joshi et al. 2016b; Kelemu and Collmer 1993; Mattinen et al. 2007; Mehta and Rosato 2001). Four LacI family genes ( $l f a R, l f c R$, lfdR, and $l f e R$ ) in $D$. dadantii 3937 were found to be important for infection (Van Gijsegem et al. 2008). Moreover, the expression of the adjacent genes controlled by LfaR and LfgR was specifically induced when the culture medium was supplemented with crude plant extract (Van Gijsegem et al. 2008). The application of functional genomics and proteomics to plant pathogens and their hosts provides a unique opportunity to identify important proteins underlying plant pathogenesis (Babujee et al. 2007; Joshi et al. 2016a; Mattinen et al. 2007; Mehta et al. 2008; Quirino et al. 2010; Rodionov et al. 2004; Wang et al. 2016). Nevertheless, the initial

${ }^{\dagger}$ Corresponding author: J. Fan; E-mail: fanjq@ njau.edu.cn

The first two authors contributed equally to this research.

*The $\boldsymbol{e}$-Xtra logo stands for "electronic extra" and indicates that two supplementary figures and one supplementary table are published online.

(C) 2017 The American Phytopathological Society interaction between plant pathogens of SREs and their host plants remains only partially understood.

To identify bacterial genes that are activated by the plant during the course of their interaction, Cai et al. (2009) constructed a mariner transposon carrying a promoterless kanamycin resistance gene to screen for potential genes induced in Mesorhizobium tianshanense by plant extracts. The gene misA, encoding a putative LysE family translocator, was identified as being activated by legume extracts. Canavanine was further identified as the inducing compound in plant extracts (Cai et al. 2009).

In recent years, colored calla (Zantedeschia spp.) is becoming one of the top-ranked ornamental plants worldwide (Fan et al. 2011b; Snijder et al. 2004b). However, due to a lack of effective control measurements, soft rot caused by $P$. carotovorum subsp. carotovorum is still a major disease on colored calla, and prevents the worldwide development of this ornamental plant (Snijder et al. 2004a). To identify virulenceassociated genes induced by plant extract, we constructed a mariner transposon insertion mutant library of the $P$. carotovorum subsp. carotovorum strain PccS1, which was isolated from diseased colored calla (Z. elliotiana) cultivar 'Black Magic' plants in Nanjing (Gu et al. 2009). We characterized an essential gene $r p l Y$ encoding ribosomal protein L25, which was activated by Z. elliotiana extract. The phenotypic results showed that $r p l Y$ contributes to virulence of PccS1 which, to our knowledge, is the first time $r p l Y$ has been described in the pathogenesis of $P$. carotovorum subsp. carotovorum.

\section{MATERIALS AND METHODS}

Bacterial strains, plasmids, and growth condition. All bacterial strains and plasmids used in this study are listed in Table 1. P. carotovorum subsp. carotovorum strain PccS1 and its derivatives were maintained on 2YT (tryptone at $17 \mathrm{~g} \cdot \mathrm{liter}^{-1}, \mathrm{NaCl}$ at $5 \mathrm{~g} \cdot \mathrm{liter}^{-1}$, and yeast extract at $10 \mathrm{~g} \cdot \mathrm{liter}^{-1}, \mathrm{pH}=7.0$ ) or minimal medium (hereafter MM) (Kersey et al. 2012) at $28^{\circ} \mathrm{C}$, and Escherichia coli was cultured on Luria-Bertani (LB) medium (Wang et al. 2016) or LB agar (LA) plates at $37^{\circ} \mathrm{C}$. When required, antibiotics were supplemented at the following final concentrations: chloramphenicol $(\mathrm{Cm})$ at $100 \mu \mathrm{g} \cdot \mathrm{ml}^{-1}$, kanamycin $(\mathrm{Km})$ at $40 \mu \mathrm{g} \cdot \mathrm{ml}^{-1}$, rifampin (Rif) at $100 \mu \mathrm{g} \cdot \mathrm{ml}^{-1}$, gentamicin $(\mathrm{Gm})$ at $100 \mu \mathrm{g} \cdot \mathrm{ml}^{-1}$, and ampicillin (Amp) at $100 \mu \mathrm{g} \cdot \mathrm{ml}^{-1}$. 
Plant extract of yellow-flowered Z. elliotiana ('Black Magic') was prepared as previously described (Wang et al. 2016). Briefly, the leaves of 7- to 8-week-old Z. elliotiana potted plants growing in the greenhouse (temperature varying from 22 to $28^{\circ} \mathrm{C}, 16 \mathrm{~h}$ day length and approximately $80 \%$ relative humidity) were collected. After being surface-sterilized with $75 \%$ ethanol, $10 \mathrm{~g}$ of leaf tissue was ground with $40 \mathrm{ml}$ of sterilized water in a blender. The mixtures were adjusted to a final volume of $50 \mathrm{ml}$ with sterilized water. The samples were then filtered twice through gauze (Yierkang, Nanchang, China). The filtrates were centrifuged at $4,000 \times g$ for $20 \mathrm{~min}$. To ensure that the plant extract constituents remained chemically similar to their in planta status, supernatants were filter sterilized by passage through a $0.22-\mu \mathrm{m}$ filter (Dongkang, Tianjin, China) to remove bacteria, and followed by ultra-filtration (Millipore, Red Bank, NJ) twice to eliminate proteins larger than $5 \mathrm{kDa}$ (Mattinen et al. 2007). Finally, the filtrates containing $20 \%$ plant extract (wt/vol) were filter sterilized again, dispensed into approximately $2-\mathrm{ml}$ aliquots and stored at $-20^{\circ} \mathrm{C}$. After conducting pretests, 2 YT and MM containing 3\% (wt/vol) Z. elliotiana leaf extract ( $2 \mathrm{YT}+\mathrm{ZE}$ and $\mathrm{MM}+\mathrm{ZE}$, respectively) were used in subsequent tests.

Construction of a transposon insertion mutant library and screen for virulence-attenuated mutants. A transposontagging insertional mutant library of PccS1 was constructed as described previously (Cai et al. 2009; Judson and Mekalanos 2000). Briefly, E. coli

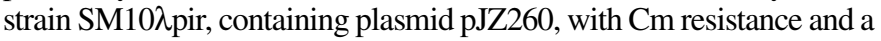
promoterless kanamycin resistance transposon, was used as the donor strain. The rifampin-resistant PccS1 strain was used as the recipient in biparental mating. Transconjugants with constitutive and plant extractinduced $\mathrm{Km}$ resistant $\left(\mathrm{Km}^{\mathrm{r}}\right)$ were obtained on 2 YT plates containing $3 \%$ $\mathrm{ZE}$ (wt/vol), Cm, Rif and $\mathrm{Km}$. All the transconjugants exhibiting $\mathrm{Km}^{\mathrm{r}}$ were then patched in parallel onto two plates (2YT containing $\mathrm{Km}, \mathrm{Cm}$ and Rif with or without plant extract) to select plant extract-induced $\mathrm{Km}^{\mathrm{r}}$ mutants. The virulence of these mutants was tested as described below. Finally, the candidates were confirmed by PCR with the primers designed according to the specific gene sequences of the transposon and PccS1.

Identification of genes in the plant extract-induced $\mathrm{Km}^{\mathrm{r}}$ and virulence-attenuated mutants. The transposon insertion sites of mutant strains were identified as previously described (Judson and Mekalanos 2000). The plant extract-dependent transposon randominsertion mutants with attenuated virulence were separately digested with SalI. The fragments were ligated into SalI-digested pUC19 and then transformed into the E. coli strain DH5 $\alpha$. Transformants were selected on LA plates containing $\mathrm{Cm}$. The colonies were then confirmed by PCR using the transposon tagging primers Km-1 and 137-1, and positive PCR products were sequenced. The sequences were analyzed by BLASTn of the NCBI database.

Genetic manipulation. Genetic manipulations, including gene deletion and complemented strain of the mutation, were performed as previously described (Li et al. 2010; Wang et al. 2016). Briefly, primers were designed according to the sequences of the flanking regions of the target genes. Fragments upstream and downstream of the gene were ligated with the $\mathrm{Km}^{\mathrm{r}}$ gene fragment amplified from pET30 (Table 1), and then recycled and cloned into pEX18GM (Table 1) to yield pEX-rplY for gene disruption. Plasmid $\mathrm{pEX}-r p l Y$ was further cloned into the $E$. coli strain BW20676 to generate a donor strain. With the wild-type strain of PccS1 used as the recipient, transconjugants were constructed by homologous recombination. To select candidate disruption mutants, transconjugants were plated onto 2YT containing $10 \%$ sucrose (Solarbio, Beijing, China) and Rif at $100 \mu \mathrm{g} \mathrm{ml}^{-1}$, Km at $40 \mu \mathrm{g} \mathrm{ml}^{-1}$, and $\mathrm{Gm}$ at $100 \mu \mathrm{g} \mathrm{ml}^{-1}$. Colonies with resistance to sucrose and kanamycin were isolated. To construct the complemented strains, the target gene and its promoter region were amplified and cloned into a broad-host-range vector pBBR1-MCS5 (Table 1). The generated vector pBBRCP-rplY (Table 1) was introduced into each respective mutant by conjugation as described above. The complemented strains were selected based on Gm resistance. All constructs were verified by PCR and sequencing. The complemented strains, carrying the target gene fusion with an epitope tagging fragment (DYKDDDDK) at the C-terminus, were additionally confirmed by western immunoblotting for the expected FLAG-tagged protein (de Bruin et al. 2011). The chromosomal rplY::lacZ transcriptional fusion was constructed by cloning the promoter region of $r p l Y$ into pVIK112, and the resulting construct was then transferred into PccS1 by conjugation using E. coli BW20676 (Cai et al. 2009). The positive

TABLE 1. Strains and plasmids used in this study

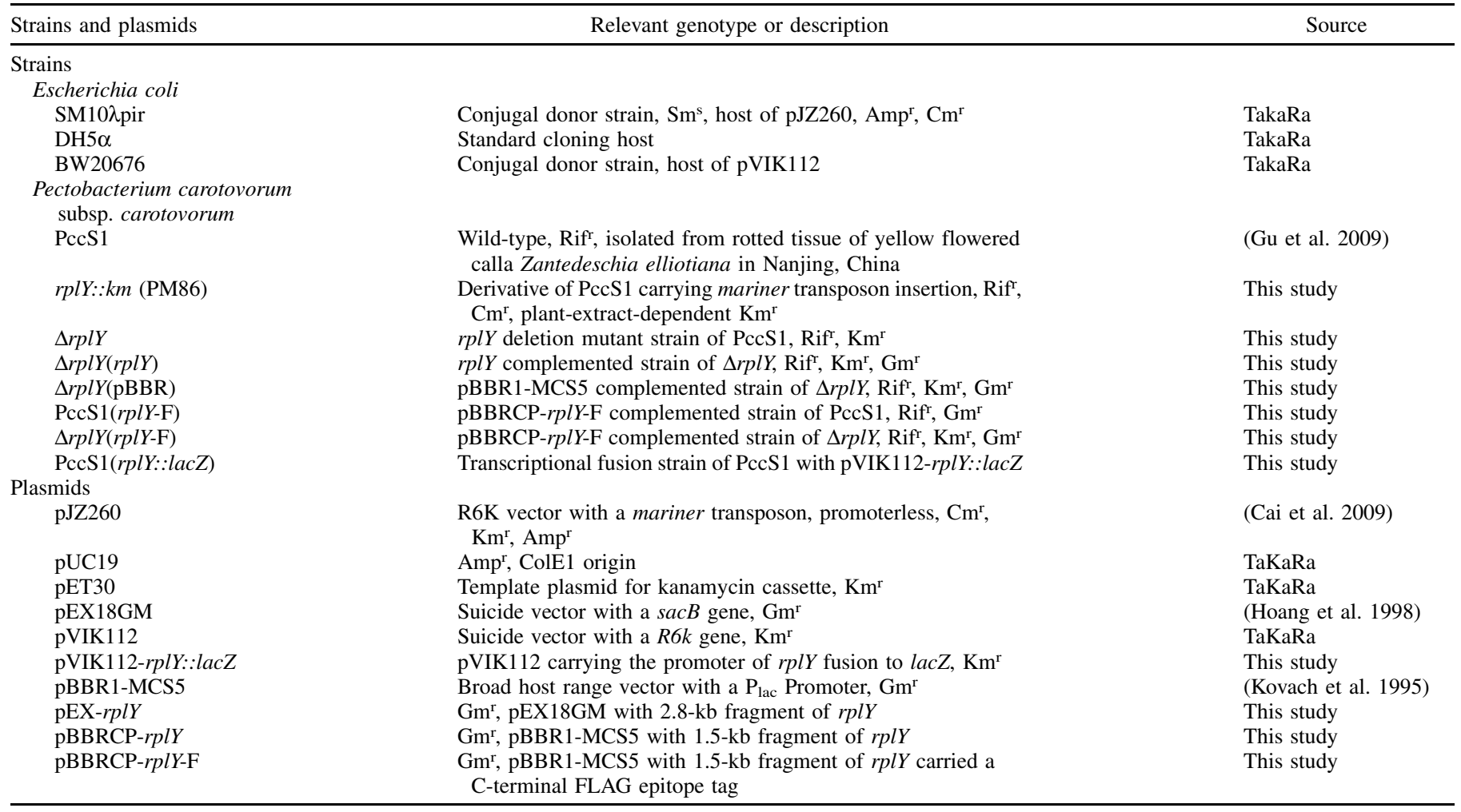


strains were verified by PCR assays targeting $r p l Y$-promoter- 1 and LacZ-2 and DNA sequencing.

Quantitative real-time PCR (qRT-PCR). The transcript levels of the target genes were measured by qRT-PCR as previously described (Kersey et al. 2012; Wang et al. 2016). Briefly, bacteria were cultured in LB from a $1 \%$ dilution of overnight cultures originating from a single colony and harvested by centrifugation when the $\mathrm{OD}_{600}$ value reached $\sim 1.0$. To determine whether the gene was induced by components of plant extract, cells of the wild-type PccS1 strain cultured both in $\mathrm{MM}$ and in $\mathrm{MM}+\mathrm{ZE}$ for 4, 8, 12, 16, and $20 \mathrm{~h}$ were also harvested by the same method. After washing with RNA-free water three times, total RNA was extracted separately using the E.Z.N.A. Bacterial RNA Kit (OMEGA, Norcross, GA). Two milligrams of RNA was then used to synthesize cDNA according to the manufacturer's instructions for the PrimeScript RT Reagent (Perfect Real Time) Kit (TaKaRa, Dalian, China). qRT-PCR was performed in an ABI 7500 Sequence Detection System (Applied Biosystems, Carlsbad, CA) using iTaq Universal SYBR Green Supermix (Bio-Rad, Hercules, CA). The gene-specific primers, including genes for virulence factors and other genes of interest, are listed in Supplementary Table S1. The housekeeping gene, $r e c A$, was used as an endogenous control for assessing expression (Kersey et al. 2012; Li et al. 2010). Three independent biological experiments were carried out with at least three replicates in each experiment. The data were analyzed by the ABI 7500 software (v.2.0.6).

$\boldsymbol{\beta}$-galactosidase activity assay. Cells containing the rplY:: lac $Z$ transcriptional fusion were cultured in $\mathrm{MM}$ and $\mathrm{MM}+\mathrm{ZE}$ for $20 \mathrm{~h}$ at $28^{\circ} \mathrm{C}$ until the stationary phase was reached $\left(\mathrm{OD}_{600}=2.0\right)$. These cultures were used for a $\beta$-galactosidase activity assay, as previously described (Cai et al. 2009), using the $\beta$-galactosidase assay kit (GENMED Scientifics Inc., Shanghai, China) with O-nitrophenyl$\beta$-D-galactopyranoside (ONPG) as a substrate. All experiments were conducted three times with at least five replicates in each assay.

Western blot analysis. To visualize the expression of the target gene induced by Z. elliotiana plant extract, the complemented strain of PccS1 carrying the target gene fusion, with an epitope tagging fragment (DYKDDDDK) at the C-terminus, was blotted as previously described (Sonnleitner and Blasi 2014). Cells were cultured overnight in $2 \mathrm{YT}$ at $28^{\circ} \mathrm{C}$, centrifuged, pelleted and washed with sterilized water. Cells were then resuspended and diluted 1:100 in $50 \mathrm{ml}$ of fresh $\mathrm{MM}$ and $\mathrm{MM}+\mathrm{ZE}$, and then cultured at $28^{\circ} \mathrm{C}$ for $4,8,12,16$, and $20 \mathrm{~h}$. Twenty-five milliliters of the cultures were then collected and pelleted by centrifugation $(4,000 \times g)$ for $5 \mathrm{~min}$. The pellet was then washed with PBS ( $\mathrm{pH} 7.0$ ) three times, and resuspended in radioimmunoprecipitation assay (RIPA) lysates (1\% Triton X-100, 1\% deoxycholate, $0.1 \%$ SDS, added at $5 \mu \mathrm{l}$ per $\mathrm{mg}$ of cells). Phenylmethanesulfonyl fluoride, protease inhibitors, and phosphatase inhibitors were added to the samples at a ratio of 1:100 (vol/vol) of RIPA, and the mixtures were incubated on ice for $3 \mathrm{~h}$. The supernatants were obtained after centrifugation at $4,000 \times g$ for $10 \mathrm{~min}$ and dispensed for further analysis. An Easy II Protein Quantitative Kit (BCA) (TRANSGEN, Beijing, China) was used to adjust the total protein of each sample to the same level. In accordance with the manufacturer's instructions, the assay was conducted in 96-well microplates as follows: a 5- $\mu$ l sample was added to $200 \mu \mathrm{l}$ of BCA working reagent and the plates were incubated at $37^{\circ} \mathrm{C}$ for $30 \mathrm{~min}$. The absorbance of the samples was then analyzed at $595 \mathrm{~nm}$. For the western blot assay, samples were boiled for $10 \mathrm{~min}$ with $4 \times$ Protein SDS-PAGE (sodium dodecyl sulfate-polyacrylamide gel electrophoresis) Loading Buffer (TaKaRa, Dalian, China). Twenty microliters of each sample was loaded onto a $12 \%$ SDS-polyacrylamide gel (Bio-Rad), transferred to a nitrocellulose membrane (Bio-Rad), and then transferred to a PVDF membrane (Millipore, Red Bank, NJ). The membranes were then blocked with 5\% milk in Tris-buffered saline containing Tween $0.05 \%$ (TBST, $\mathrm{pH}=7.5$ ), and incubated with a 1:5,000 dilution of the primary DYKDDDDK-Tag (3B9) Mouse mAb (Abmart, Berkeley Heights, $\mathrm{NJ}$ ) for $1 \mathrm{~h}$. The membrane was then washed twice with TBST and incubated with a 1:10,000 dilution of Goat Anti-Mouse IgG-HRP
(Abmart) for $1 \mathrm{~h}$, and washed three times with TBST. Peroxidase was detected using the ECL Western Blotting Substrate (Bio-Rad). AntiRNA polymerase (anti-RNAP) polyclonal antibody (Institute of Microbiology, Chinese Academy of Science, Beijing, China) was used as the loading control (Deng et al. 2014).

Phenotypic assays. The plant virulence assay was conducted on leaves as previously described ( $\mathrm{Li}$ et al. 2010; Wang et al. 2016). Briefly, PccS1 and its derivative strains were cultured overnight in $2 \mathrm{YT}$ at $28^{\circ} \mathrm{C}$. The cells were harvested and suspended in sterilized water or $3 \% \mathrm{ZE}$ plant extract to $\mathrm{OD}_{600} 1.2\left(10^{8} \mathrm{CFU} \mathrm{ml}^{-1}\right)$ for inoculation. Approximately 45-day-old leaves were detached from $Z$. elliotiana, Z. aethiopica, and Chinese cabbage (Brassica rapa subsp. pekinensis) plants grown in a greenhouse. The detached leaves were washed thoroughly with sterilized water and surface-sterilized with $75 \%$ ethanol. For each site, the abaxial surface of the leaves was punctured with a sterilized tooth pick, and $10 \mu \mathrm{l}$ of bacterial suspension was applied in parallel onto the wounds. Sterilized water was inoculated as a negative control. The leaf pieces were then incubated in a moist chamber at $28^{\circ} \mathrm{C}$, and the maceration area $\left(\mathrm{cm}^{2}\right)$ on the leaves was measured at $16 \mathrm{~h}$ after inoculation (HAI). The virulence assays were conducted three times using 5 to 10 leaf pieces in each assay.

To assess the colonization of the strains, $10 \mu \mathrm{l}$ of the diluted cells of the appropriate cultures of the wild-type and mutant PccS1 strains was inoculated onto the leaves of $Z$. elliotiana as described above. The macerated tissues $(\sim 0.5 \times 0.5 \mathrm{~cm})$ were detached from the leaves, weighed, and ground in sterilized water at a volume of $1 \mathrm{ml}$. The cell suspension from the rotted tissue was subjected to 10 -fold serial dilution and patched onto three LA replica plates. After incubation at $28^{\circ} \mathrm{C}$ for $16 \mathrm{~h}$, colonies were counted. The experiment was repeated three times, and the CFU per gram of rotted tissue was quantified.

Growth curves were established as follow. Cells of PccS1 and its derivatives were cultured overnight, harvested, and suspended in sterilized water to an $\mathrm{OD}_{600}$ of 0.6. Cell suspensions were then diluted to a concentration of $1 \%(\mathrm{vol} / \mathrm{vol})$ in $50 \mathrm{ml}$ of the appropriate medium without antibiotics, and the $\mathrm{OD}_{600}$ value was monitored at four hour intervals until stationary phase with a Beckman DU-640 (Beckman, Houston, TX).

To examine the pleiotropic effects of $r p l Y$ on the virulence of PccS1, a number of phenotypes were investigated. Motility was tested by measuring the area $\left(\mathrm{mm}^{2}\right)$ of swimming haloes on a $2 \mathrm{YT}$ plate (containing $0.3 \%$ agar) $24 \mathrm{~h}$ after $2.5 \mu \mathrm{l}$ of the cell suspension (in sterilized water adjusted to $\mathrm{OD}_{600} \sim 1.0$ ) was spotted onto the plate (Fan et al. 2011a; Wang et al. 2009). Motility was also monitored by observing the sedimentation of the cells in stationary glass tubes for $24 \mathrm{~h}$ at room temperature after shaking the culture in $2 \mathrm{YT}$ at $28^{\circ} \mathrm{C}$ until the $\mathrm{OD}_{600}$ reached 2.0.

Biofilm development on an abiotic surface was quantified using crystal violet, as previously described (O'Toole and Kolter 1998; Zeng et al. 2013). Briefly, cells were cultured in 2 YT broth in tubes at $28^{\circ} \mathrm{C}$ until the $\mathrm{OD}_{600}$ reached 2.0. The cultures were then removed, $1 \%$ crystal violet was added to them at the same volume as the cultures. The inner walls of the tubes were then stained for $1 \mathrm{~h}$ at room temperature, rinsed three times with sterilized water and air-dried for $2 \mathrm{~h}$. Tubes were photographed and crystal violet was then eluted with $1 \mathrm{ml}$ of $100 \%$ ethanol. The crystal violet elution was quantified by measuring the light absorbance at $575 \mathrm{~nm}$.

The PCWDE activity of the wild-type PccS1 and derived mutants was determined. Overnight cultures were harvested by centrifugation and diluted with $\mathrm{LB}$ broth to a concentration of 2.0 at $\mathrm{OD}_{600}$. A total of $2.5 \mu \mathrm{l}$ of the diluted cell suspension was spotted onto protease assay plates (LA medium supplemented with 10\% sterilized skimmed milk), as well as pectate lyase and cellulase assay plates, as previously described (Barnard et al. 2010). PCWDE production was visualized on the plates after cells were spotted onto the plates and incubated for $48 \mathrm{~h}$ at $28^{\circ} \mathrm{C}$. Positive colonies on the protease activity assay plates exhibited clear haloes on an opaque white background. Pectate lyase assay plates were stained with $7.5 \%$ (wt/vol) copper acetate for $1 \mathrm{~h}$, and positive colonies were identified based on the presence of double cream haloes 
on a translucent blue-green background. Cellulase activity assay plates were flooded with $0.2 \%$ (wt/vol) Congo red for $20 \mathrm{~min}$, bleached with $1 \mathrm{M} \mathrm{NaCl}$ for $15 \mathrm{~min}$, and then stained with $1 \mathrm{M} \mathrm{HCl}$ for $5 \mathrm{~min}$. Positive colonies were recognized based on the presence of off-white haloes on a dark blue background. Finally, the areas $\left(\mathrm{mm}^{2}\right)$ of the haloes were measured. All phenotypic assays were conducted three times with at least five replicates per independent experiment.

Data were statistically analyzed using SPSS 14.0 (SPSS Inc., Chicago, IL). The hypothesis test of percentages (Duncan's multiple range test, $P=0.05$ or 0.01 ) was used to determine significant difference in the assays described above.

\section{RESULTS}

Only one mariner insertion mutant showed both plant extract-dependent $\mathrm{Km}^{\mathbf{r}}$ and attenuated virulence. To identify genes that were activated by $Z$. elliotiana plant extract and related to virulence, a promoter-trap transposon was introduced into

\section{P. caro_PccS1 \\ P. aro_PC1 \\ P. caro_PCC21 \\ P. caro_WPP14 \\ P. bra_PBR1692 \\ P. wa_WPP163 \\ P. wa_SCC3193 \\ P. wa_3304 \\ P. atro_SCRI1043 \\ D. dad Ech586 \\ E. coli_MG1655 \\ V. cho_V51}
P. caro_PccS1
P. aro_PC1
P. caro_PCC21
P. caro_WPP14
P. bra PBR1692
P. wa_WPP163
P. wa_SCC3193
P. wa_3304
P. atro_SCRI1043
D. dad Ech586
E. coli_MG1655
V. cho V51

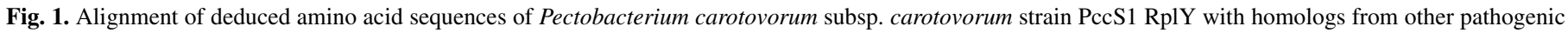

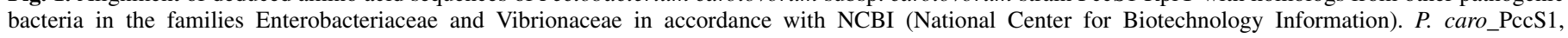

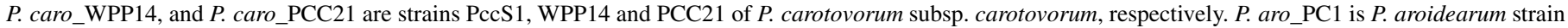

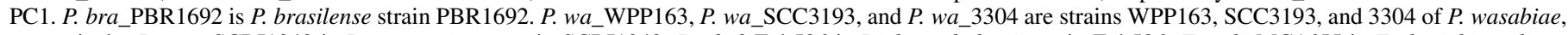

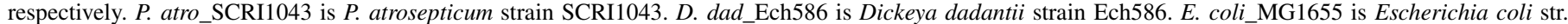

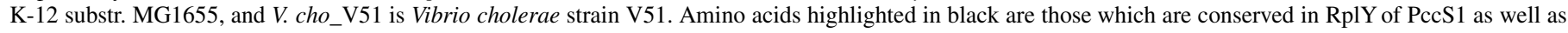
other pathogenic bacteria strains in the families Enterobacteriaceae and Vibrionaceae.

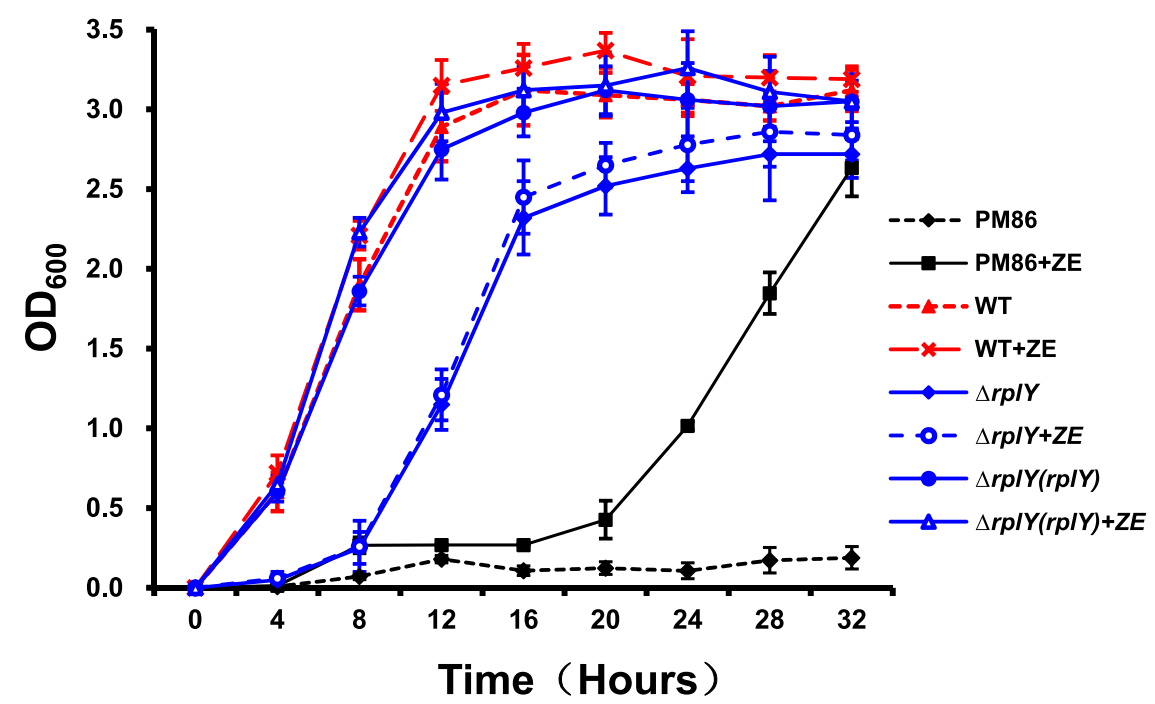

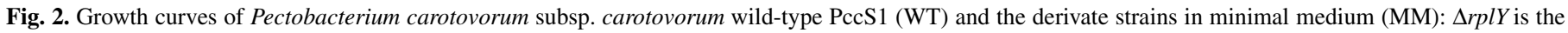

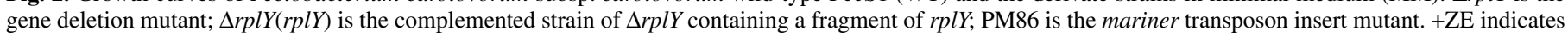

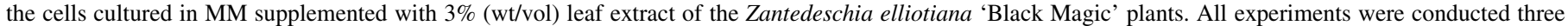
times with at least three replicates in each assay. The results are shown as the averages \pm standard deviation. 
P. carotovorum subsp. carotovorum strain PccS1 (Cai et al. 2009). The promoterless kanamycin resistance gene was randomly inserted into wild-type PccS1, and a library comprising approximately 6,000 mutants was generated. A total of 500 insertion mutants displayed $\mathrm{Km}^{\mathrm{r}}$ in the presence of plant extract but only one, PM86, showed

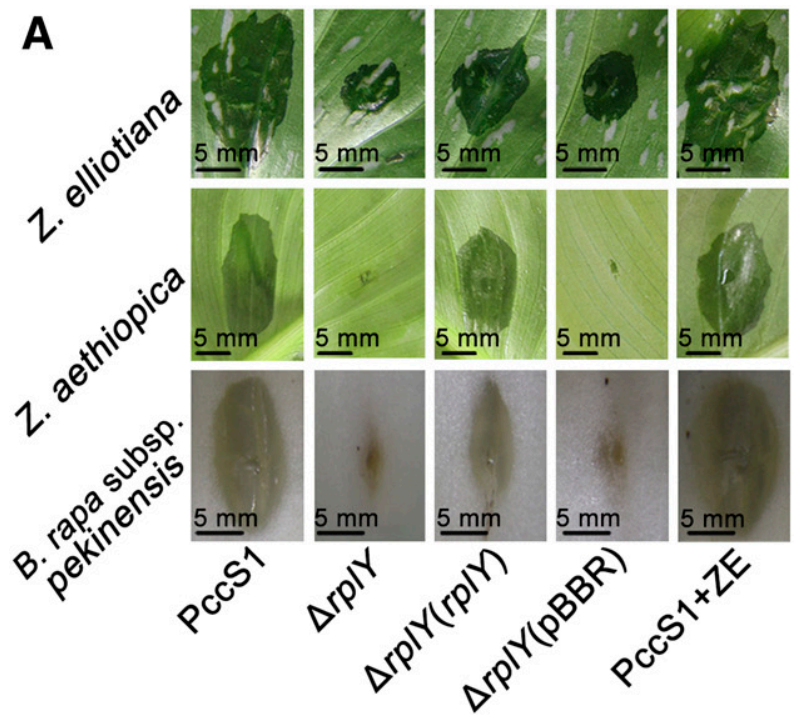

B

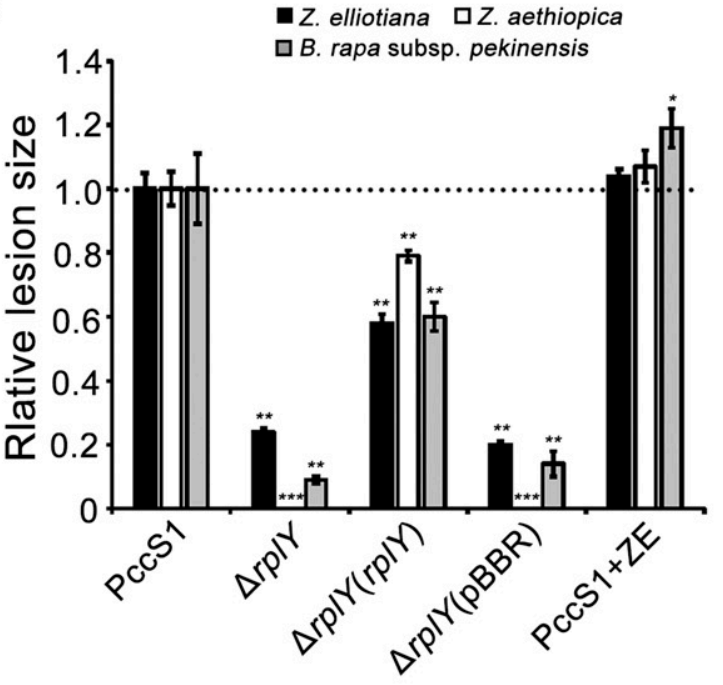

C

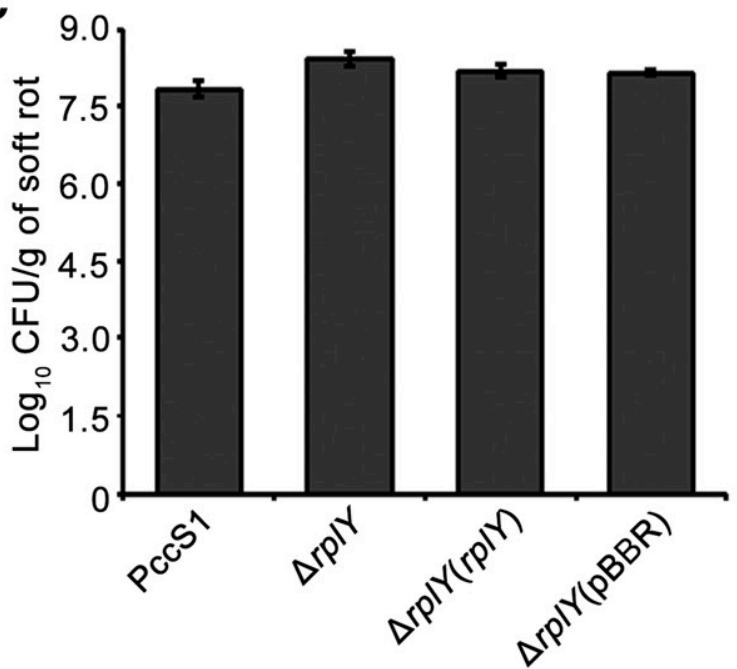

attenuated virulence on yellow-flowered calla (Z. elliotiana), calla lily (Z. aethiopica), and Chinese cabbage (Brassica rapa subsp. pekinensis) compared with the wild-type PccS1 (Supplementary Fig. $\mathrm{S} 1$ ). The other insertion mutants with plant extract-dependent $\mathrm{Km}^{\mathrm{r}}$ caused wild-type virulence levels in host tissue.

$r p l Y$ was identified at the site of the transposon insertion in PM86. DNA from the positive transformants on LA containing $\mathrm{Cm}$ was amplified by a PCR assay using the transposon tagging primers Km-1 and 137-1. The products were sequenced and analyzed by BLASTn of the NCBI database, and the gene at the site of transposon insertion in PM86 was identified as $r p l Y$. rplY is $285 \mathrm{bp}$ in length and encodes 95 amino acid residues of ribosomal protein L25 (RplY). RplY in PccS1 is identical to that in $P$. aroidearum strain $\mathrm{PC} 1$ isolated from monocotyledonous plant (Nabhan et al. 2013), which is conserved and shares around 93 to $94 \%$ similarity with other Pectobacterium spp. strains isolated from dicotyledonous plants, including $P$. carotovorum PCC21 and WPP14, P. brasiliense PBR1692, P. wasabiae WPP163, SCC3193 and 3304, and P. atrosepticum SCRI1043. When compared with other Enterobacteriaceae and Vibrionaceae species such as D. dadantii strain Ech586, E. coli strain MG1655, and Vibrio cholera strain V51, the RplY protein in PccS1 also shares 77, 70, and $61 \%$ identity, respectively (Fig. 1).

Plant extract induces bacterial growth in media. PM86 grew at wild-type levels in rich media (LB), and no difference showed in the growth of PM86 or the wild-type PccS1 in LB with and without plant extract (Supplementary Fig. S2). When cultured in MM or MM + ZE, PM86 showed attenuated growth in both conditions before $20 \mathrm{~h}$. However, when cultured for an additional $12 \mathrm{~h}$, the $\mathrm{OD}_{600}$ of PM86 in MM + ZE almost increased to wild-type levels at stationary phase. In contrast, the $\mathrm{OD}_{600}$ value of PM86 in MM did not exceed 0.2 by 32 h (Fig. 2).

rplY contributes to $P$. carotovorum subsp. carotovorum virulence on plant leaves. As the transposon used to mutate target gene rplY might also affect genes in the flanking regions of $r p l Y$, we constructed a gene-deletion mutant of PccS1 $(\Delta r p l Y)$ using homologous recombination. We also constructed a complemented strain $\Delta r p l Y(r p l Y)$ and a mutant containing the empty vector $\Delta r p l Y(\mathrm{pBBR})$. The deletion in $r p l Y$ delayed the growth of the mutant in $\mathrm{MM}$ or $\mathrm{MM}+$ $\mathrm{ZE}$ for $16 \mathrm{~h}$ during the exponential growth phase but there were no significant differences in growth between these strains grown in MM or $\mathrm{MM}+\mathrm{ZE}$ for $32 \mathrm{~h}$ (Fig. 2). The virulence of the wild-type PccS1 and mutant strains was determined on leaves of host plants from three different genera/species, namely Z. elliotiana, Z. aethiopica and B. rapa subsp. pekinensis. Compared with wild-type PccS1, $\Delta r p l Y$ was significantly attenuated in its ability to macerate these host

Fig. 3. Tissue maceration and bacterial population in planta of Pectobacterium carotovorum subsp. carotovorum strains: PccS1 (wild-type strain); $\Delta r p l Y$ (gene deletion mutant); $\Delta r p l Y(r p l Y)(\Delta r p l Y$ complemented with the fragment of $r p l Y)$; and $\Delta r p l Y(\mathrm{pBBR})(\Delta r p l Y$ complemented with the empty vector carrying plasmid pBBR). $+\mathrm{ZE}$, cells suspended with $3 \%(\mathrm{wt} / \mathrm{vol})$ leaf extract of Zantedeschia elliotiana plants. A, Ten microliters of diluted bacterial cells $\left(\mathrm{OD}_{600}=1.2\right)$ of the appropriate cultures suspended with sterilized water (or $\mathrm{ZE}$ ) was inoculated in parallel onto the leaves of colored calla (Z. elliotiana 'Black Magic'), calla lily (Z. aethiopica), and Chinese cabbage (Brassica rapa subsp. pekinensis). Photographs were taken $16 \mathrm{~h}$ after inoculation. B, Relative rate of the maceration area caused by the mutant strains compared with that caused by the wild-type PccS1 on the three hosts. Maceration area caused by PccS1 suspended by sterilized water is set to 1 . The asterisks indicate a significant difference in lesion size caused by inoculation with the mutant strains versus PccS1 suspended in sterilized water. C, Quantities of the cells recovered from the macerated tissue per gram of rotted leaves of Z. elliotiana $16 \mathrm{~h}$ after inoculation. The experiments were repeated three times with at least 5 internal replicates in each. The results are shown as averages \pm standard deviation. $* P<0.05$; $* * P<0.01$; $* * * P<0.001$, versus wild-type PccS1, Duncan's multiple range test. 
plants, while the complemented strain $\Delta r p l Y(r p l Y)$ partially restored this macerating ability (Fig. 3A and B). However, $\Delta r p l Y$ showed no reduction in colonization in Z. elliotiana leaves compared with the wild-type (Fig. 3C).

Deletion mutant $\Delta r p l Y$ exhibits reduced PCWDE activities and motility but has no effect on biofilm formation. The PCWDEs activities of the wild-type PccS1, $\Delta r p l Y, \Delta r p l Y(r p l Y)$, and $\Delta r p l Y(\mathrm{pBBR})$ strains were determined at $48 \mathrm{~h}$ after the cells were spotted onto assay plates. The PCWDEs activities were all significantly attenuated when gene $r p l Y$ was deleted, and reduced activities were partially restored in the complemented strain $\Delta r p l Y$ ( $r p l Y$ ) (Fig. 4A to $\mathrm{C}$ and $\mathrm{E}$ ).

The results of qRT-PCR demonstrated that the expression of the genes encoding protease ( $p r t W$ ) and pectate lyase (pel6) in $\Delta r p l Y$ were significantly reduced at the transcriptional level. However, the deletion mutant exhibited a nonsignificant decrease in celC (cellulase) expression compared with the wild-type PccS1 (Fig. 4F).

The deletion mutant $\Delta r p l Y$ also showed a reduction in swimming motility on $0.3 \%$ 2YT agar plates and produced a sediment more quickly when cultured in tubes (Fig. 4D and G). qRT-PCR analysis showed that the transcript expression level of the flagellin gene $(f l i C)$ was significantly decreased in $\Delta r p l Y$ (Fig. 4F). Although FliC plays a crucial role in bacterial movement (Roessler and Muller 2002; Wang et al. 2007), transmission electron microscopy revealed that the flagella of
$\Delta r p l Y$ appeared similar in structure to those of the wild-type strain (data not shown). The result of crystal violet staining showed that deletion of $r p l Y$ had no effect on biofilm formation by PccS1 (Fig. 4H and I).

Gene $r p l Y$ is induced by plant extract. To demonstrate whether $r p l Y$ was activated in the presence of plant extract, a chromosomal $r p l Y:$ : lacZ transcriptional fusion construct was designed. The promoter was significantly induced by the Z. elliotiana plant extract (Fig. 5A). PccS1 cells grown in MM + ZE showed higher expression levels of gene $r p l Y$. In the presence of plant extract, $r p l Y$ was significantly upregulated at the 8-, 12-, and 16-h time-points, and particularly at $12 \mathrm{~h}$ (Fig. 5B). Moreover, the results of western blot analysis consolidated the finding that RplY expression was activated by plant extract. When cultured in $\mathrm{MM}+\mathrm{ZE}, \mathrm{PccS} 1$ cells produced more RplY protein than those in MM at 4, 12, 16, and $20 \mathrm{~h}$ (Fig. 5B).

\section{DISCUSSION}

RplY belongs to the ribosomal protein L25 family and has 92 to 95 amino acid residues (Fig. 1). RplY is bound independently to ribosomal 5S rRNA along with two other proteins RplE (L5) and RplR (L18), and forms a separate domain of the ribosome in E. coli (Lu and Steitz 2000). The protein sequence of RplY is highly conserved in strains of Pectobacterium isolated from monocotyledonous plants (Fig. 1), which might support the novel species $P$. aroidearum proposed
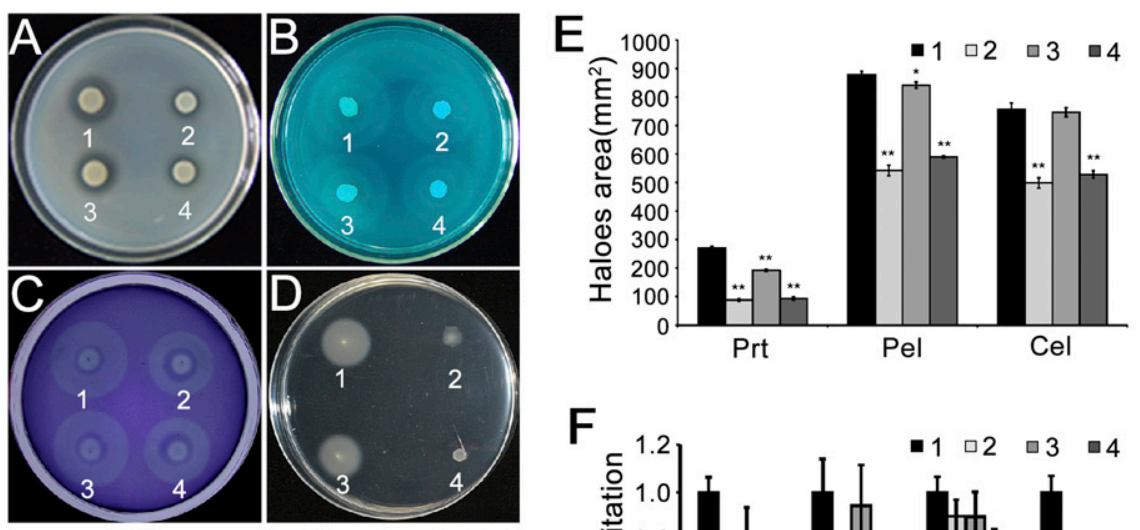

\section{$\mathbf{F}$}
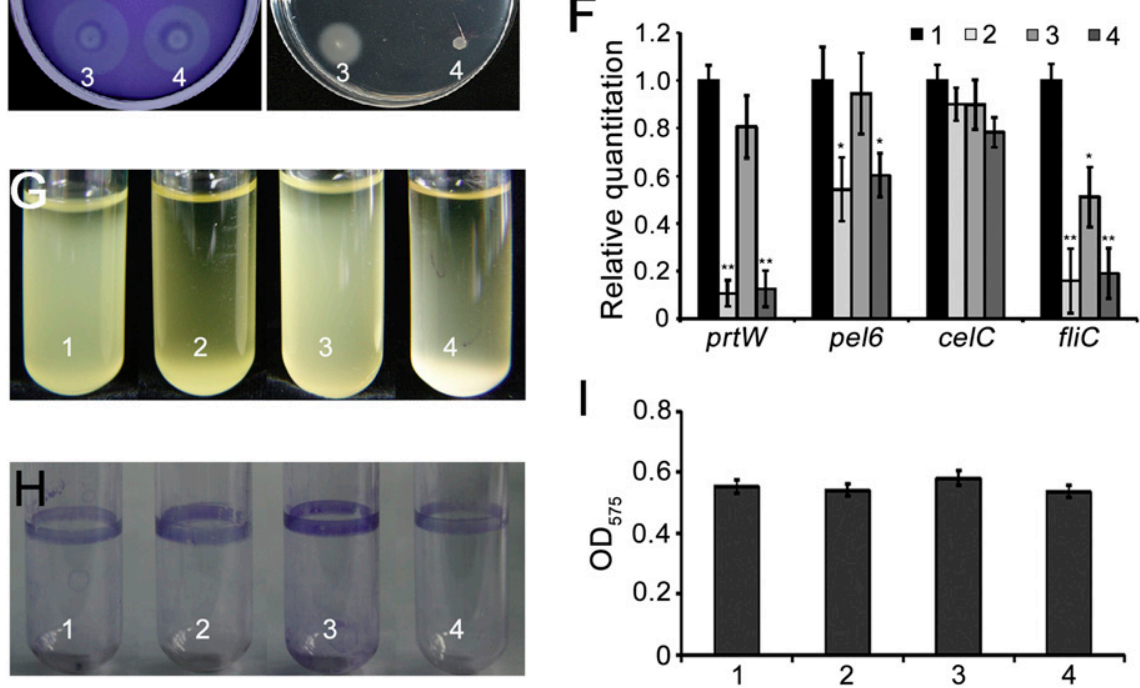

Fig. 4. Pleiotropic effects of rplY on Pectobacterium carotovorum subsp. carotovorum PccS1. From A to I, 1, wild-type strain PccS1; 2, gene deletion mutant $\Delta r p l Y ; 3, \Delta r p l Y$ complemented with the fragment of $r p l Y$; and 4, strain of $\Delta r p l Y$ complemented with the empty vector carrying plasmid pBBR. A, B, and C, The plant cell wall-degrading enzymes (PCWDEs) activities were determined visually by the production of a clear halo around the colonies for protease, by double cream haloes around the colonies for pectate lyase, and by an off-white halo around the colonies for cellulase $48 \mathrm{~h}$ after the cells had been patched onto the assay plates. D, Swimming motility of the cells was represented by a halo on a clear background $24 \mathrm{~h}$ after inoculation on $0.3 \%$ agar plates. E, Bars indicate the halo areas on the different assay plates for the PCWDEs. Prt, Pel, and Cel are for protease, pectate lyase, and cellulase, respectively. F, Bars represent relative mRNA levels of the genes encoding the PCWDEs (prtW, pel6, and celC) and flagellin $(f l i C)$ in the wild-type PccS1 and the strains derived from PccS1 determined by quantitative real-time polymerase chain reaction. The housekeeping gene recA was used as an endogenous control. G, Sedimentation of the cells in glass tubes statically placed for $24 \mathrm{~h}$ at room temperature after it had been oscillated in $2 \mathrm{YT}$ at $28^{\circ} \mathrm{C}$ until the $\mathrm{OD}_{600}$ reached 2.0 . $\mathbf{H}$, Biofilm development on the abiotic surface was revealed by the cells attached to the inner wall of the tubes and stained with crystal violet. I, Quantification of the biofilm measured by light absorbance at $575 \mathrm{~nm}$ of crystal violet eluted from the inner walls of the tubes. The experiments were repeated three times with at least 5 internal replicates. The results are shown as averages \pm standard deviation. $* P<0.05$; $* * P<0.01$, versus the wild-type PccS1, Duncan's multiple range test. 
by Nabhan in 2013 (Nabhan et al. 2013). RplY is essential for the production of mature 25S rRNA in Saccharomyces cerevisiae (Van Beekvelt et al. 2001), and is a surface-exposed protein that acts as an antigen recognizable by the host immune response in the animal pathogens Neisseria meningitidis and Rickettsia heilongjiangensis (Mendum et al. 2009; Qi et al. 2013).

Our results showed that $r p l Y$ is important for the production of major PCWDEs in P. carotovorum subsp. carotovorum. Although expression of cellulase gene celC showed a nonsignificant decrease at the transcriptional level in $\Delta r p l Y$, it exhibited significantly attenuated cellulase activity on plates, which may be as a result of reduced celC expression at the translational level. Although we have no information on RplY in ribosomal assembly in $P$. carotovorum subsp. carotovorum, in the model species E. coli and $S$. cerevisiae, RplY is one of the ribosomal proteins bound to 5S rRNA and 25S rRNA, respectively (Lu and Steitz 2000; Van Beekvelt C. A. et al. 2001), 5S rRNA is one of components of the large subunit of the ribosome in all organisms. The large subunit catalyzes peptide bond formation via the enzyme peptidyltransferase (Woolford and Baserga 2013), so we speculate that reduced celC expression at the translational level might result from an impaired ribosomal protein in the absence of RplY.

In previous studies, it was revealed that motility is an important determinant of pathogenesis in P. carotovorum subsp. carotovorum (Hossain et al. 2005). Our motility assays (swimming and sedimentation) also suggest that, due to the additional effects on PCWDEs, RplY has a pleiotropic effect on the virulence of $P$. carotovorum subsp. carotovorum. Another ribosomal protein $\mathrm{S} 12$ (RpsL) in P. carotovorum subsp. carotovorum was also found with pleiotropic effects on virulence (Barnard et al. 2010). Barnard carried out a screen for transposon-induced $P$. carotovorum subsp.
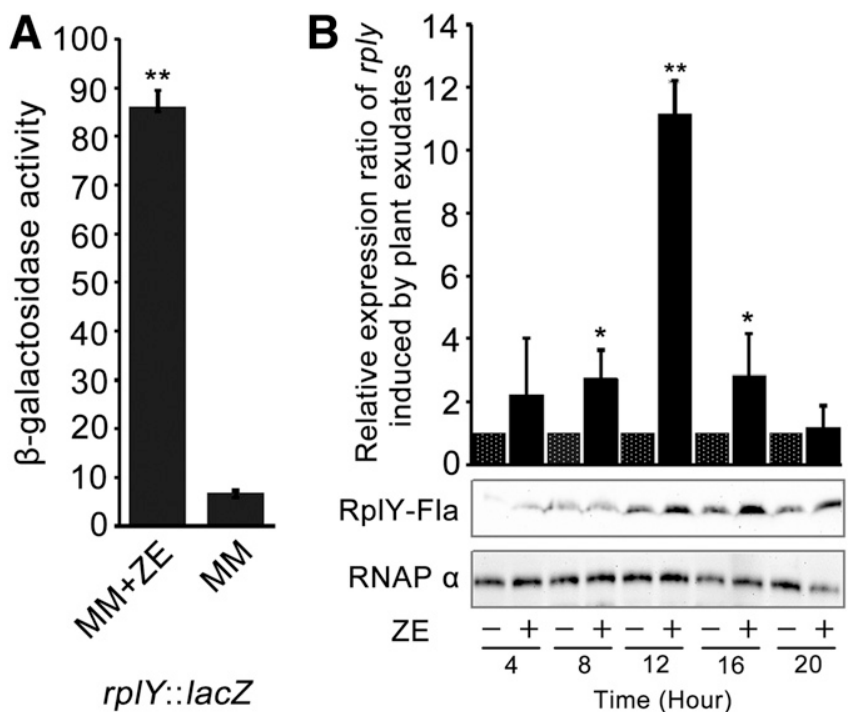

Fig. 5. Expression of rplY and RplY in Pectobacterium carotovorum subsp. carotovorum strain PccS1 induced by plant extract. A, The cells of PccS1 containing the $r p l Y:: l a c Z$ transcriptional fusion were grown to an $\mathrm{OD}_{600}$ of 2.0 in minimal medium (MM) and MM supplemented with 3\% (wt/vol) plant extract of Zantedeschia elliotiana $(\mathrm{MM}+\mathrm{ZE})$. Cells were harvested and the $\beta$-galactosidase activities were determined. Bars depict the values of $\beta$-galactosidase conferred by the transcriptional $r p l Y:: l a c Z$ fusion in the presence or absence of plant extract. B, Relative mRNA levels of $r p l Y$ were determined by quantitative real-time polymerase chain reaction (qRT-PCR) in PccS1 cultured in minimal medium (MM) and MM supplemented with $3 \% \mathrm{ZE}$ (wt/vol) for 4, 8, 12, 16, and $20 \mathrm{~h}$. The mRNA levels of rplY in the cells cultured in MM were set to 1 to calculate the relative expression ratio. The expression of flag-tagged RplY in PccS1 cultured in MM and MM supplemented with $3 \% \mathrm{ZE}$ (wt/vol) was analyzed by western blotting at the same time points as qRT-PCR. RNAP $\alpha$ was used as the loading control. The experiments were repeated three times with at least five internal replicates in each independent experiment. The results are shown as averages \pm standard deviation. ${ }^{*} P<0.05 ; * * P<0.01$, versus the cells cultured in $\mathrm{MM}$, Duncan's multiple range test. carotovorum mutants showing defects in the production of carbapenem (Car), and identified such mutants that were also affected in virulence and PCWDE production. The mutants did not appear to carry the transposon but rather were affected by a single base change in the rpsL locus, resulting in the substitution of the wild-type lysine by threonine or asparagine at codon 43 (Barnard et al. 2010).

The reduced growth of PM86 in MM in the absence of plant extract might be directly linked to its attenuated virulence on plant leaves. Therefore, the virulence assays with PM86 were kept under observation over $32 \mathrm{~h}$. However, although PM86 grew as well as the wild-type in rich media (LB), and PM86 populations reached wildtype levels at $32 \mathrm{HAI}$ in MM $+\mathrm{ZE}$, the lesion area at $32 \mathrm{HAI}$ in the plant assay did not increase above that seen at 16 HAI. These results suggest that the attenuated virulence of PM86 resulted from impairment of $r p l Y$ rather than reduction in bacterial population growth. The results also suggest that $r p l Y$ is important for $P$. carotovorum subsp. carotovorum virulence.

The virulence of wild-type PccS1 increased on all three host plants when cells were suspended with $3 \%$ (wt/vol) plant extract from leaves of $Z$. elliotiana compared with sterilized water, although the differences were significant only on the leaves of B. rapa subsp. pekinensis (Fig. 3A and $\mathrm{B}$ ). This is consistent with findings from previous studies in which extracts from the host plants of soft rot bacterial pathogens, such as carrot, potato, and celery, contain uncharacterized constituents that can induce pathogen virulence (Kersey et al. 2012). Since proteins larger than $5 \mathrm{kDa}$ in the plant extract were removed, inducers in the extract are likely to be small molecules, as reviewed previously (Charkowski et al. 2012). Further studies are needed to characterize these putative inducers and to clarify the mechanisms underlying their effects on bacteria.

By recruiting compounds of plant extract as signals, pathogens modify the expression of genes to overcome host plant resistance (Kersey et al. 2012). In the present study, a total of 500 PccS1 mutants exhibited plant-extract-dependent kanamycin resistance. However, only rplY could be induced in the presence of Z. elliotiana extract, and PccS1 displayed attenuated virulence when $r p l Y$ was impaired by insertion of the mariner transposon. Populations of the insertion mutant, PM86, increased to higher levels in MM + ZE than in $\mathrm{MM}$ after $20 \mathrm{~h}$, suggesting that the plant extract might have nutrient effects on bacterial growth. However, growth of wild-type PccS1, $\Delta r p l Y$ and $\Delta r p l Y(r p l Y)$ increased slightly but not significantly in MM + ZE compared with MM (Fig. 2). Hence, we infer that the role of plant extract in bacterial growth is not as a nutrient source but rather acts as an inducer. This was further supported by the results of the rplY::lacZ transcriptional fusion report system and expression of $r p l Y$ at transcriptional and translational levels in the wild-type PccS1 in the present of plant extract (Fig. 5).

Over the past several decades, proteomics, transcriptomics, and genomics studies have facilitated our understanding of bacteriaplant interactions (Bell et al. 2004; Judson and Mekalanos 2000; Mattinen et al. 2007; Nykyri et al. 2012; Toth et al. 2006). However, some crucial proteins are expressed at low levels that are undetectable by current approaches. In the present study, we showed that RplY was mainly expressed at low levels when $P$. carotovorum subsp. carotovorum strain PccS1 was grown in MM for $20 \mathrm{~h}$. Interestingly, this protein was produced at a higher level in MM + ZE. RplY was not detected in the profiles of two-dimensional electrophoresis (2-DE) when we analyzed differentially expressed proteins in in vivo and in vitro interactions between PccS1 and Z. elliotiana (Wang et al. 2016).

In summary, we characterized gene $r p l Y$ at the site of a random insertion by the mariner transposon, which was induced by plant extract and required for full virulence of $P$. carotovorum subsp. carotovorum strain PccS1. Our results suggest that transposon screening for potential virulence-related genes represents a complementary approach to omics studies, especially for proteins that are expressed at low levels during bacteria-plant interactions. 


\section{ACKNOWLEDGMENTS}

We thank J. Zhu and Z. Zhong (Nanjing Agricultural University, Nanjing, China) for providing the plasmid pJZ260 V6K vector with the mariner transposon and W. Qian (Institute of Microbiology, Chinese Academy of Science, Beijing, China) for the gift of anti-RNA polymerase polyclonal antibody. We also thank R. R. Walcott (University of Georgia, Athens, GA) and I. Toth (James Hutton Institute, Dundee, UK) for critical revisions of this manuscript. This work was funded by the Special Fund for AgroScientific Research in the Public Interest of China (grant 201303015), the China National Key Technology Support Program (2012BAD14B02), and the Special Fund for Construction of the Agricultural Public Service System in Nanjing (2015).

\section{LITERATURE CITED}

Babujee, L., Venkatesh, B., Yamazaki, A., and Tsuyumu, S. 2007. Proteomic analysis of the carbonate insoluble outer membrane fraction of the soft-rot pathogen Dickeya dadantii (syn. Erwinia chrysanthemi) strain 3937. J. Proteome Res. 6:62-69.

Barnard, A. M., Simpson, N. J., Lilley, K. S., and Salmond, G. P. 2010. Mutations in rpsL that confer streptomycin resistance show pleiotropic effects on virulence and the production of a carbapenem antibiotic in Erwinia carotovora. Microbiology 156:1030-1039.

Bell, K. S., Sebaihia, M., Pritchard, L., Holden, M. T., Hyman, L. J., Holeva, M. C., Thomson, N. R., Bentley, S. D., Churcher, L. J. C., Mungall, K., Atkin, R., and Bason, N. 2004. Genome sequence of the enterobacterial phytopathogen Erwinia carotovora subsp. atroseptica and characterization of virulence factors. Proc. Natl. Acad. Sci. USA 101:11105-11110.

Cai, T., Cai, W., Zhang, J., Zheng, H., Tsou, A. M., Xiao, L., Zhong, Z., and Zhu, J. 2009. Host legume-exuded antimetabolites optimize the symbiotic rhizosphere. Mol. Microbiol. 73:507-517.

Charkowski, A., Blanco, C., Condemine, G., Expert, D., Franza, T., and Hayes, C. 2012. The role of secretion systems and small molecules in soft-rot enterobacteriaceae pathogenicity. Annu. Rev. Phytopathol. 50:425-449.

de Bruin, O. M., Duplantis, B. N., Ludu, J. S., Hare, R. F., Nix, E. B., Schmerk, C. L., Robb, C. S., Boraston, A. B., Hueffer, K., and Nano, F. E. 2011. The biochemical properties of the Francisella pathogenicity island (FPI)-encoded proteins IglA, IglB, IglC, PdpB and DotU suggest roles in type VI secretion. Microbiology 157:3483-3491.

Deng, C., Deng, A., Sun, S., Wang, L., Wu, J., Wu, Y., Chen, X., Fang, R., Wen, T., and Qian, W. 2014. The periplasmic PDZ domain-containing protein Prc modulates full virulence, envelops stress responses, and directly interacts with dipeptidyl peptidase of Xanthomonas oryzae pv. oryzae. Mol. Plant-Microbe Interact. 27:101-112.

Fan, J. Q., Qian, G. L., Chen, T., Zhao, Y. Q., Liu, F. Q., Walcott, R. R., and Hu, B. S. 2011a. The acyl-homoserine lactone (AHL)-type quorum sensing system affects growth rate, swimming motility and virulence in Acidovorax avenae subsp. citrulli. World J. Microbiol. Biotechnol. 27:1155-1166.

Fan, J. Q., Qian, G. L., Yang, X., Gu, C. Y., Kang, Y. J., Ma, Y., Hu, B. S., and Liu, F. Q. 2011b. Biocontrol of bacterial soft rot of calla lily by elicitor Harpin $_{\text {Xoo }}$ and $N$-acyl homoserine lactonase (AttM). World J. Microbiol. Biotechnol. 27:401-410.

Gu, C. Y., Fan, J. Q., Yang, X., Hu, B. S., and Liu, F. Q. 2009. Identification of the pathogen and quorum quenching study on bacterial soft rot of colored calla lily. J. Nanjing Agric. Univ. 32:71-77.

Hassan, S., Shevchik, V. E., Robert, X., and Hugouvieux-Cotte-Pattat, N. 2013. PelN Is a new pectate lyase of Dickeya dadantii with unusual characteristics. J. Bacteriol. 195:2197-2206.

Hoang, T. T., Karkhoff-Schweizer, R. R., Kutchma, A. J., and Schweizer, H. P. 1998. A broad-host-range Flp-FRT recombination system for site-specific excision of chromosomally-located DNA sequences: Application for isolation of unmarked Pseudomonas aeruginosa mutants. Gene 212:77-86.

Hogan, C. S., Mole, B. M., Grant, S. R., Willis, D. K., and Charkowski, A. O. 2013. The type III secreted effector DspE is required early in solanum tuberosum leaf infection by Pectobacterium carotovorum to cause cell death, and requires $\mathrm{Wx}(3-6) \mathrm{D} / \mathrm{E}$ motifs. PLoS One 8:e65534.

Hossain, M. M., Shibata, S., Aizawa, S. I., and Tsuyumu, S. 2005. Motility is an important determinant for pathogenesis of Erwinia carotovora subsp. carotovora. Physiol. Mol. Plant Pathol. 66:134-143.

Jin, L., Ham, J. H., Hage, R., Zhao, W., Soto-Hernandez, J., Lee, S. Y., Paek, S.-M., Kim, M. G., Boone, C., Coplin, D. L., and Mackey, D. 2016. Direct and indirect targeting of PP2A by conserved bacterial type-III effector proteins. PLoS Pathog. 12:e1005609.

Joshi, J. R., Burdman, S., Lipsky, A., Yariv, S., and Yedidia, I. 2016a. Plant phenolic acids affect the virulence of Pectobacterium aroidearum and P. carotovorum ssp. brasiliense via quorum sensing regulation. Mol. Plant Pathol. 17:487-500.
Joshi, J. R., Khazanov, N., Senderowitz, H., Burdman, S., Lipsky, A., and Yedidia, I. 2016b. Plant phenolic volatiles inhibit quorum sensing in pectobacteria and reduce their virulence by potential binding to ExpI and ExpR proteins. Sci. Rep. 6:38126.

Judson, N., and Mekalanos, J. J. 2000. TnAraOut, A transposon-based approach to identify and characterize essential bacterial genes. Nat. Biotechnol. 18:740-745.

Kazemi-Pour, N., Condemine, G., and Hugouvieux-Cotte-Pattat, N. 2004. The secretome of the plant pathogenic bacterium Erwinia chrysanthemi. Proteomics 4:3177-3186.

Kelemu, S., and Collmer, A. 1993. Erwinia chrysanthemi Ec16 produces a second set of plant inducible pectate lyase isozymes. Appl. Environ. Microbiol. 59:1756-1761.

Kersey, C. M., Agyemang, P. A., and Dumenyo, C. K. 2012. CorA, the magnesium/nickel/cobalt transporter, affects virulence and extracellular enzyme production in the soft rot pathogen Pectobacterium carotovorum. Mol. Plant Pathol. 13:58-71.

Kovach, M. E., Elzer, P. H., Hill, D. S., Robertson, G. T., Farris, M. A., Roop, R. M., 2nd, and Peterson, K. M. 1995. Four new derivatives of the broadhost-range cloning vector pBBR1MCS, carrying different antibioticresistance cassettes. Gene 166:175-176.

Kubheka, G. C., Coutinho, T. A., Moleleki, N., and Moleleki, L. N. 2013. Colonization patterns of an mCherry-tagged Pectobacterium carotovorum subsp. brasiliense strain in potato plants. Phytopathology 103:1268-1279.

Li, Y., Yamazaki, A., Zou, L., Biddle, E., Zeng, Q., Wang, Y., Lin, H., Wang, Q., and Yang, C. H. 2010. ClpXP protease regulates the type III secretion system of Dickeya dadantii 3937 and is essential for the bacterial virulence. Mol. Plant-Microbe Interact. 23:871-878.

Lu, M., and Steitz, T. A. 2000. Structure of Escherichia coli ribosomal protein L25 complexed with a 5S rRNA fragment at 1.8-angstrom resolution. Proc. Natl. Acad. Sci. USA 97:2023-2028.

Lu, Y., Rashidul, I. M., Hirata, H., and Tsuyumu, S. 2011. KdgR, an IClR family transcriptional regulator, inhibits virulence mainly by repression of hrp genes in Xanthomonas oryzae pv. oryzae. J. Bacteriol. 193:6674-6682.

Ma, B., Hibbing, M. E., Kim, H. S., Reedy, R. M., Yedidia, I., Breuer, J., Glasner, J. D., Perna, N. T., Kelman, A., and Charkowski, A. O. 2007. Host range and molecular phylogenies of the soft rot enterobacterial genera Pectobacterium and Dickeya. Phytopathology 97:1150-1163.

Mansfield, J., Genin, S., Magori, S., Citovsky, V., Sriariyanum, M., Ronald, P., Dow, M., Verdier, V., Beer, S. V., Machado, M. A., Toth, I., Salmond, G., and Foster, G. D. 2012. Top 10 plant pathogenic bacteria in molecular plant pathology. Mol. Plant Pathol. 13:614-629.

Mattinen, L., Nissinen, R., Riipi, T., Kalkkinen, N., and Pirhonen, M. 2007. Host-extract induced changes in the secretome of the plant pathogenic bacterium Pectobacterium atrosepticum. Proteomics 7:3527-3537.

Mehta, A., Brasileiro, A. C., Souza, D. S., Romano, E., Campos, M. A., Grossi-de-Sa, M. F., Silva, M. S., Fanco, O. L., Fragoso, R. R., Bevitori, R., and Rocha, T. L. 2008. Plant-pathogen interactions: What is proteomics telling us? FEBS J. 275:3731-3746.

Mehta, A., and Rosato, Y. B. 2001. Differentially expressed proteins in the interaction of Xanthomonas axonopodis pv. citri with leaf extract of the host plant. Proteomics 1:1111-1118.

Mendum, T. A., Newcombe, J., McNeilly, C. L., and McFadden, J. 2009. Towards the immunoproteome of Neisseria meningitidis. PLoS One 4: e5940.

Nabhan, S., De Boer, S. H., Maiss, E., and Wydra, K. 2013. Pectobacterium aroidearum sp. nov., a soft rot pathogen with preference for monocotyledonous plants. Int. J. Syst. Evol. Microbiol. 63:2520-2525.

Nykyri, J., Niemi, O., Koskinen, P., Nokso-Koivisto, J., Pasanen, M., Broberg, M., Plyusnin, I., Toronen, P., Holm, L., Pirhonen, M., and Palva, E. T. 2012. Revised phylogeny and novel horizontally acquired virulence determinants of the model soft rot phytopathogen Pectobacterium wasabiae SCC3193. PLoS Pathog. 8:e1003013.

O'Toole, G. A., and Kolter, R. 1998. Initiation of biofilm formation in Pseudomonas fluorescens WCS365 proceeds via multiple, convergent signaling pathways: A genetic analysis. Mol. Microbiol. 28:449-461.

Potrykus, M., Sledz, W., Golanowska, M., Slawiak, M., Binek, A., Motyka, A., Zoledowska, S., Czajkowski, R., and Lojkowska, E. 2014. Simultaneous detection of major blackleg and soft rot bacterial pathogens in potato by multiplex polymerase chain reaction. Ann. Appl. Biol. 165:474-487.

Qi, Y., Xiong, X., Wang, X., Duan, C., Jia, Y., Jiao, J., Gong, W., and Wen, B. 2013. Proteome analysis and serological characterization of surfaceexposed proteins of Rickettsia heilongjiangensis. PLoS One 8:e70440.

Quirino, B. F., Candido, E. S., Campos, P. F., Franco, O. L., and Kruger, R. H. 2010. Proteomic approaches to study plant-pathogen interactions. Phytochemistry 71:351-362.

Rodionov, D. A., Gelfand, M. S., and Hugouvieux-Cotte-Pattat, N. 2004. Comparative genomics of the KdgR regulon in Erwinia chrysanthemi 3937 and other gamma-proteobacteria. Microbiology 150:3571-3590. 
Roessler, M., and Muller, V. 2002. Chloride, a new environmental signal molecule involved in gene regulation in a moderately halophilic bacterium, Halobacillus halophilus. J. Bacteriol. 184:6207-6215.

Snijder, R. C., Cho, H.-R., Hendriks, M. M. W. B., Lindhout, P., and van Tuyl, J. M. 2004a. Genetic variation in Zantedeschia spp. (Araceae) for resistance to soft rot caused by Erwinia carotovora subsp. carotovora. Euphytica 135: 119-128.

Snijder, R. C., Lindhout, P., and van Tuyl, J. M. 2004b. Genetic control of resistance to soft rot caused by Erwinia carotovora subsp carotovora in Zantedeschia spp. (Araceae), section Aestivae. Euphytica 136:319-325.

Sonnleitner, E., and Blasi, U. 2014. Regulation of Hfq by the RNA CrcZ in Pseudomonas aeruginosa carbon catabolite repression. PLoS Genet. 10: e1004440.

Tian, Y., Zhao, Y., Xie, H., Wang, X., Fan, J., and Hu, B. 2015. First report of bacterial soft rot of seleng wormwood caused by Pectobacterium carotovorum subsp. carotovorum in China. Plant Dis. 99:1175-1176.

Toth, I. K., Bell, K. S., Holeva, M. C., and Birch, P. R. 2003. Soft rot erwiniae: From genes to genomes. Mol. Plant Pathol. 4:17-30.

Toth, I. K., and Birch, P. R. 2005. Rotting softly and stealthily. Curr. Opin. Plant Biol. 8:424-429.

Toth, I. K., Pritchard, L., and Birch, P. R. J. 2006. Comparative genomics reveals what makes an enterobacterial plant pathogen. Annu. Rev. Phytopathol. 44:305-336.

Van Beekvelt, C. A., De Graaff-vincent, M., Faber, A. W., Van't Riet, J., Venema, J., and Raue, H. A. 2001. All three functional domains of the large ribosomal subunit protein L25 are required for both early and late pre-rRNA processing steps in Saccharomyces cerevisiae. Nucleic Acids Res. 29: 5001-5008.
Van Gijsegem, F., Wlodarczyk, A., Cornu, A., Reverchon, S., and Hugouvieux-Cotte-Pattat, N. 2008. Analysis of the LacI family regulators of Erwinia chrysanthemi 3937, involvement in the bacterial phytopathogenicity. Mol. Plant-Microbe Interact. 21:1471-1481.

Wang, D., Korban, S. S., and Zhao, Y. 2009. The Rcs phosphorelay system is essential for pathogenicity in Erwinia amylovora. Mol. Plant Pathol. 10:277-290.

Wang, H., Yang, Z., Du, S., Ma, L., Liao, Y., Wang, Y., Toth, I., and Fan, J. 2016. Characterisation of Pectobacterium carotovorum proteins differentially expressed during infection of Zantedeschia elliotiana in vivo and in vitro which are essential for virulence. Mol. Plant Pathol. (Published online.) doi:10.1111/mpp.12493

Wang, Q. F., Zhao, Y. F., McClelland, M., and Harshey, R. A. 2007. The RcsCDB signaling system and swarming motility in Salmonella enterica serovar Typhimurium: Dual regulation of flagellar and SPI-2 virulence genes. J. Bacteriol. 189:8447-8457.

Williamson, N. R., Commander, P. M., and Salmond, G. P. 2010. Quorum sensing-controlled Evr regulates a conserved cryptic pigment biosynthetic cluster and a novel phenomycin-like locus in the plant pathogen, Pectobacterium carotovorum. Environ. Microbiol. 12:1811-1827.

Woolford, J. L., and Baserga, S. J. 2013. Ribosome biogenesis in the yeast Saccharomyces cerevisiae. Genetics 195:643-681.

Yamazaki, A., Li, J., Hutchins, W. C., Wang, L., Ma, J., Ibekwe, A. M., and Yang, C. H. 2011. Commensal effect of pectate lyases secreted from Dickeya dadantii on proliferation of Escherichia coli O157:H7 EDL933 on lettuce leaves. Appl. Environ. Microbiol. 77:156-162.

Zeng, Q., McNally, R. R., and Sundin, G. W. 2013. Global small RNA chaperone Hfq and regulatory small RNAs are important virulence regulators in Erwinia amylovora. J. Bacteriol. 195:1706-1717. 